\title{
Farklı malç materyallerinin marul (Lactuca sativa L. Duna) bitkisinin gelişimi ve bazı mineral besin elementleri üzerine etkisi
}

Effect of different mulch materials on growth and some mineral nutrients of lettuce (Lactuca sativa $\mathrm{L}$. Duna)

\author{
Hasan ÖZ $Z^{1 \mathscr{C}}$, Cennet YAYLACI ${ }^{2}$, ibrahim ERDAL ${ }^{2}$ iD \\ ${ }^{1}$ Isparta Uygulamalı Bilimler Üniversitesi, Ziraat Fakültesi, Tarımsal Yapılar ve Sulama Bölümü, Isparta. \\ ${ }^{2}$ Isparta Uygulamalı Bilimler Üniversitesi, Ziraat Fakültesi, Toprak Bilimi ve Bitki Besleme Bölümü, Isparta.
}

MAKALE BILGISI / ARTICLE INFO

Makale tarihçesi / Article history:

DOI: $10.37908 /$ mkutbd.935445

Geliş tarihi /Received:10.05.2021

Kabul tarihi/Accepted:07.07.2021

\section{Keywords:}

Bubble PE mulch, fabric mulch, lettuce, mineral nutrition.

\footnotetext{
Corresponding author: Hasan ÖZ

$\varangle$ : hasanoz@isparta.edu.tr
}

\author{
ÖZET / A B STR A C T
}

\begin{abstract}
Aims: In this study, it was aimed to determine the effect of the use of plastic (PE) and fabric materials with different colors and properties on the growth and mineral nutrition of lettuce plant.

Methods and Results: The research was conducted for 2 years in greenhouse conditions in 2018-2019. In the study, It consists of 3 different $\mathrm{PE}$ mulch material, porous fabric material and control applications. Lettuce plant was grown as a plant material in the experiment. $\mathrm{P}, \mathrm{K}, \mathrm{Ca}, \mathrm{Mg}, \mathrm{Fe}, \mathrm{Zn}$, $\mathrm{Mn}$, and $\mathrm{Cu}$ analyzes were made with the dry weight values of the lettuce plant harvested at the end of the cultivation period and the differences between the applications were revealed. When the data obtained in the control group on plant dry weight for both years were compared with other applications, it was determined that the most effective mulch applications were transparent PE mulch and bubble PE mulch applications. The effects of the treatments on the $P$ and $C a$ concentrations of the plants were found to be significant for both years, while the effects on the $K$ and $\mathrm{Mg}$ concentrations were significant for only one year. The effects of the applications on the micro element concentrations of the plant were generally found to be significant for both years. It has been determined that the amount of nutrients removed varies according to different mulch applications. If a general evaluation is made, it has been observed that the highest intake of nutrients is realized by plants grown under Ş-PE mulch and B-PE mulch applications.

Conclusions: It was observed that the highest lettuce microelement concentrations for both years were obtained from control application, and the effects of the other applications on the micro element concentrations of the plant were generally similar

Significance and Impact of the Study: When a general evaluation was made regarding the effect of mulch applications on nutrient concentrations of the plant, it was seen that the nutrient concentrations of plants with lower plant dry weight values were higher. The highest nutrient uptake was generally seen in transparent PE mulch and bubble PE mulch.
\end{abstract}

Atıf / Citation: Öz H, Yaylacı C, Erdal i (2021) Farklı malç materyallerinin marul (Lactuca sativa L. Duna) bitkisinin gelişimi ve bazı mineral besin elementleri üzerine etkisi. MKU. Tar. Bil. Derg. 26(2) : 489-496. DOI: $10.37908 /$ mkutbd. 935445 


\section{Giriş}

Toprak malçlama, dünya çapında yetiştirilen ürünlerde, özellikle sebze yetiştiriciliğinde kullanılan ve yetiştiricilikte pek çok avantaj sağlayan bir yöntemdir (Moreno ve ark., 2016). Malçlama, toprak sıcaklığını koruma ve artırmanın yanı sıra, yabancı ot kontrolü ile su tutma kapasitesini artırarak üründe erkenciliği teşvik etmektedir ve tüm bu faktörler verimin artmasına neden olmaktadır (Mutetwa ve Mtaita, 2014; Haque ve ark., 2018; Zhao ve ark., 2014; Zangoueinejad ve ark., 2018). Bununla birlikte, bu etkiler toprak tipine, iklime ve malçlama için kullanılan malzemeye göre değişkenlik göstermektedir (Ghosh ve ark., 2006).

Malçlama, saman gibi organik malzemelerle veya plastik filmler gibi inorganik malzemelerle yapılmaktadır. Malçlama malzemesi seçimi; iklime, maliyet-fayda oranına ve yetiştirilecek ürüne bağlı olarak değişkenlik göstermektedir (Wang ve ark., 2016). Malçlama malzemeleri bitkinin yetiştirildiği yerdeki mikro iklim üzerinde doğrudan bir etkiye sahiptir ve bu da bitki fizyolojik metabolizması üzerinde olumlu veya olumsuz etkilere neden olabilmektedir (Kader ve ark., 2017). Malçlar; kuraklık stresini önlemede, donmaya karşı korunmada, toprak kimyasal, fiziksel, biyolojik özelliklerin iyileştirilmesinde, hastalık kontrolünde ve mahsul verimliliğini artırmada önemli bir etkiye sahiptir (Amare ve Desta, 2021; Cahill ve Chalker-Scott, 2005; Li ve ark., 2018; Franquera, 2015).

Plastik film, son yıllarda özellikle sebze üretiminde toprak malçlamada kullanılan ana malzeme haline gelmiştir (Steinmetz ve ark., 2016). Piyasada en yaygın kullanılan plastik malç filmi türleri siyah renk malç filmidir. Bunun yanı sıra, piyasada üretilen plastik malç filmlerinin diğer renkleri arasında gümüş, kırmızı, mavi, sarı ve yeşil filmler bulunmaktadır (Decoteau ve ark., 1988; Caruso ve ark., 2019). Plastik malç filmlerinin renklendirilmesi, farklı rengin toprak sıcaklığını ve plastik malç yüzeyini etkileyen güneş radyasyonunu emme, iletme ve yansıtma özelliği açısından farklı etkileri bulunmaktadır (Ham ve ark., 1993; Mendonça ve ark., 2021).

Marul (Lactuca sativa L.), Asteraceae familyasına ait tek yıllık bir bitkidir. Kısa yetiştiricilik süresi ve soğuk direnci nedeniyle ilkbahar ve sonbahar yetiştiriciliğinde en çok tercih edilen taze yapraklı sebzelerden biridir. Bitkilerin optimum gelişmesi; nem, besin ve ışığın etkili kullanımı yoluyla düzgün bir şekilde büyümelerini sağlar ve böylece maksimum verim elde edilmiş olur (Khazaei ve ark., 2013). Marul, kısa bir yetiştiricilik periyoduna sahip olmasına rağmen, malçlama büyüme ve gelişmeyi olumlu yönde etkilemektedir. Malçlama ile yetiştirilen marulun malç uygulanmayan bitkilere göre boy ve çaplarının arttığı belirlenmiştir. Olumlu etkinin nedeni, toprak neminin korunması ile yıkamadan kaynaklanan besin elementi kaybının azalması ve toprağın sıcaklık rejiminin iyileşmesinden kaynaklanmaktadır (Asaduzzaman ve ark., 2010; Khazaei ve ark., 2013; Moniruzzaman, 2006; Yordanova ve Nikolov, 2017).

Yüksek toprak sıcaklıkları; yeni köklerin uzunluğunu artırarak, kökler tarafından besin alımını fizyolojik olarak iyileştirerek ve topraktaki besin mineralizasyonunu hızlandırarak besinlerin bitki tarafından alınmasını kolaylaştırmaktadır. Özellikle, mineral besin maddelerinin bitkiler tarafından alınımı, sıcaklığa duyarlı sayısız kimyasal, fiziksel ve biyolojik süreçlere bağlıdır. Bu nedenle toprak sıcaklığı, dünya çapındaki karasal ekosistemlerde verimlilik üzerinde büyük bir etkiye sahiptir (Marschner, 1986).

$\mathrm{Bu}$ çalışmada, farklı renk ve özellikte plastik $(\mathrm{PE})$ ve kumaş malzemenin malç malzemesi olarak kullanımının sera koşullarında marul bitkisinin gelişimi ve mineral beslenmesi üzerine olan etkisinin belirlenmesi amaçlanmıştır. Burada ilk kez denenen balonlu PE malzemenin malç malzemesi olarak kullanılabilirliği belirlenmeye çalışılmıştır.

\section{MATERYAL VE YÖNTEM}

\section{Deneme alanı, deneme deseni ve bitki materyali}

Araştırma, Isparta ilinde, 2018-2019 yılları Şubat-Mayıs aylarında sera koşullarında yürütülmüştür. Araştırma alanı, $37^{\circ} 50^{\prime}$ kuzey enlemi ile $30^{\circ} 32^{\prime}$ doğu boylamları arasında yer almaktadır. Arazinin rakımı 1007m'dir. Araştırmanın yürütüldüğü sera, genişliği $6 \mathrm{~m}$, uzunluğu $15 \mathrm{~m}$, taban alanı $90 \mathrm{~m}^{2}$ olarak yay çatılı, çelik konstrüksiyonlu, UV+IR katkılı olarak inşa edilmiştir. Çalışma; 3 farklı PE malç malzemesi, $0.06 \mathrm{~mm}$ kalınlığında şeffaf renkli PE (Ş-PE) örtü malzemesi, üreticiler tarafından malç uygulamalarında sıklıkla kullanılan 0.04 $\mathrm{mm}$ kalınlığında siyah renkli PE (S-PE) ve piyasada hava balonlu ambalaj malzemesi olarak satılan $30 \mathrm{~mm}$ çapında, $12.5 \mathrm{~mm}$ yüksekliğinde şeffaf renkli PE (B-PE) malzemelerle birlikte $0.03 \mathrm{~mm}$ kalınlığında gözenekli kumaş malzeme (K) ile kontrol uygulamalarından oluşturulmuştur. Denemede bitki materyali olarak marul bitkisi yetiştirilmiştir. Şubat ayının son haftasında $2 \times 2 \mathrm{~m}$ boyutlarındaki parsellere $30 \times 20 \mathrm{~cm}$ aralıklarla $(20$ bitki $\mathrm{m}^{-2}$ ) Duna yedikule marul fidelerinin dikimi yapılmış ve mayısın ilk haftası hasat edilmiştir. Marul bitkisi için önerilen $110 \mathrm{~kg} \mathrm{ha}^{-1} \mathrm{~N}$ (Amonyum Sülfat), $100 \mathrm{~kg} \mathrm{ha}^{-1}$ $\mathrm{P}_{2} \mathrm{O}_{5}$ (TSP) ve $50 \mathrm{~kg} \mathrm{ha}^{-1} \mathrm{~K}_{2} \mathrm{O}$ (Potasyum Sülfat) taban gübrelemesi damla sulamayla yapılmıştır. 


\section{Deneme alanı, deneme deseni ve bitki materyali}

Deneme toprağı yüksek kireç içeriğine sahip, tuz içeriği ve organik madde içeriği düşük, hafif alkali reaksiyonlu olup killi/tın bünyeye sahiptir. Deneme alanına ait diğer bazı toprak özellikleri Çizelge 1 'de verilmiştir.

Çizelge 1. Deneme alanı toprağının bazı özellikleri

Table 1. Some characteristics of study area soil

\begin{tabular}{|c|c|}
\hline Özellik & \\
\hline Organik madde (\%) & 1.8 \\
\hline $\mathrm{CaCO}_{3}(\%)$ & 18 \\
\hline$E C\left(d s m^{-1}\right)$ & 0.98 \\
\hline Bünye & Killi tın \\
\hline $\mathrm{pH}(1 / 2.5)$ & 7.5 \\
\hline Yarayışlı P (mg kg-1) & 30 \\
\hline Değişebilir Ca $\left(\mathrm{mg} \mathrm{kg}^{-1}\right)$ & 6000 \\
\hline Değişebilir $\mathrm{K}\left(\mathrm{mg} \mathrm{kg}^{-1}\right)$ & 156 \\
\hline Değişebilir Mg (mg kg-11) & 360 \\
\hline DPTA' da extrakte edilebilen Fe $\left(\mathrm{mg} \mathrm{kg}^{-1}\right)$ & 10 \\
\hline DPTA $^{\prime}$ da extrakte edilebilen $\mathrm{Mn}\left(\mathrm{mg} \mathrm{kg}^{-1}\right)$ & 30 \\
\hline DPTA $^{\prime}$ da extrakte edilebilen $\mathrm{Zn}\left(\mathrm{mg} \mathrm{kg}^{-1}\right)$ & 2.5 \\
\hline 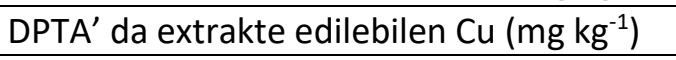 & 5 \\
\hline
\end{tabular}

\section{Toprak analizleri}

Toprak örneklerinin $\mathrm{pH}^{\prime} \mathrm{s}$ 1 $1 / 2.5$ oranında saf su ile sulandırılıp $\mathrm{pH}$ ve EC metre aracılığıyla ölçülmüştür (Richards, 1954). Toprak örneklerinin bünyeleri hidrometre yöntemine göre, kireç içerikleri ise Scheibler kalsimetresi kullanılarak belirlenmiştir. Organik madde Walkey-Black metoduna göre (Walkley ve Black, 1934), alınabilir P, Olsen metoduna göre (Olsen, 1954), değişebilir $\mathrm{K}$, Ca ve $\mathrm{Mg}$ analizleri $1 \mathrm{~N}$ Amonyum Asetat $(\mathrm{pH}=7)$ metoduna göre (Olsen, 1954) ve alınabilir $\mathrm{Fe}, \mathrm{Cu}$, $\mathrm{Zn}$ ve $\mathrm{Mn}$ analizleri ise DTPA metoduna göre (Lindsay ve Norvell, 1969) yapılmıştır.

\section{Bitki analizleri}

Deneme sonrası toprak üzerinden kesilerek hasat edilen bitkiler yapraklarına ayrıldıktan sonra çeşme suyu ve saf sudan geçirilen yaprak örnekleri sabit ağırlığa gelinceye kadar $65{ }^{\circ} \mathrm{C}$ de kurutulmuştur. Kuru ağırlıkları alındıktan sonra tüm bitki olarak öğütülmüş ve $\mathrm{P}, \mathrm{K}, \mathrm{Ca}, \mathrm{Mg}, \mathrm{Fe}, \mathrm{Zn}$, $\mathrm{Mn}$ ve $\mathrm{Cu}$ analizleri için $550{ }^{\circ} \mathrm{C}$ de kül fırınında yaklaşık 6 saat süreyle kuru yakılmıştır. Elde edilen kül, üzerine 1$2 \mathrm{ml}$ saf su ilave edilerek ıslatıldıktan sonra üzerine $4 \mathrm{ml}$ $3 \mathrm{~N} \mathrm{HCl}$ ilave edilmek suretiyle tamamen çözünmesi sağlanmıştır. Daha sonra örnekler, $100 \mathrm{ml}$ ölçü balonlarına süzülerek derecesine saf su ile tamamlanmıştır. Elde edilen süzükte $P$, sarı renk yöntemine göre spektrofotometrede, diğer besin elementleri ise atomik absorbsiyon spektrofotometresinde okunmak suretiyle belirlenmiştir (Kacar ve İnal, 2010; Barton, 1948).

\section{Besin elementi alımları}

Bitki tarafından topraktan kaldırılan besin elementi miktarı, bitkinin kuru ağırlığı (KA) ile bitkinin besin elementi içeriklerinin çarpılmasıyla elde edilmiştir.

\section{istatistiksel değerlendirme}

Araştırma tesadüf parselleri deneme desenine göre yürütülmüş ve elde edilen değerler MSTAT-C programıyla değerlendirilmiş, ortalamalar arasındaki fark DUNCAN çoklu karşılaştırma testiyle yorumlanmıştır.

\section{BULGULAR ve TARTIŞMA}

\section{Bitki kuru ağırığı ve besin elementi konsantrasyonları}

Çeşitli malç materyallerinin marulun kuru ağırlığı ile $P, K$, Ca ve $\mathrm{Mg}$ konsantrasyonlarına olan etkileri Çizelge 2 de verilmiştir. Elde edilen veriler incelendiğinde, bitki kuru ağırlıklarının farklı malç uygulamalarından istatistiksel anlamda etkilenmiş olduğu görülmüştür. Her iki yıl için de bitki kuru ağırlığı üzerine en etkili malç uygulamaların şeffaf renkli (Ş-PE; 46,99 g/bitki ve $44.40 \mathrm{~g} / \mathrm{bitki}$ ) malç ile balonlu malç (B-PE; 38,94 g/bitki) uygulamaları olduğu görülürken, kontrol grubu (15,05 g/bitki ve $14.93 \mathrm{~g} / \mathrm{bitki})$ olduğu belirlenmiştir. Elde edilen kuru ağırlık artışının malçlamadan dolayı daha iyi bir gelişme ortamının 
sağlanmasıyla ilişkili olduğu araştırıcılar tarafından bildirilmiştir (Amare ve Desta, 2021; Cahill ve ChalkerScott, 2005; Li ve ark., 2018; Franquera, 2015). Uygulamaların bitkilerin $\mathrm{P}$ konsantrasyonuna etkileri her iki yıl için de anlamlı bulunmuştur. Her iki yıl için bitkilerde belirlenen en yüksek $\mathrm{P}$ konsantrasyonu $\% 0.5$ ve $\% 0.46$ ile kontrol grubuna ait bitkilerde belirlenirken, en düşük P konsantrasyonları ilk yılda siyah (S-PE; \% 0.38) ve şeffaf (Ş-PE; \% 0.39), ikinci yılda ise kumaş ( $K$; \% 0.33) malç uygulamalarından elde edilmiştir. Engels ve Marschner (1992) fosforun diğer besin elementlerine kıyasla kök bölgesi sıcaklık değişiminden daha az etkilendiğini bildirmişlerdir (Kaçar ve Katkat, 2007). Araştırmada, kontrol grubu uygulamasında daha yüksek P konsantrasyonu belirlenmesi toprak sıcaklığı artışından etkilenmediğini göstermektedir. Malç uygulamalarının bitkinin $\mathrm{K}$ konsantrasyonu üzerine etkisi ilk yıl önemli olurken ikinci yıl uygulamalar arasında anlamlı bir farklılık belirlenmemiştir. Birinci yıl K sonuçlarına bakıldığında S-PE malç uygulaması yapılan gruba ait bitkilerin \% 4.53 ile en yüksek K konsantrasyonuna sahip oldukları, buna karşılık kontrol grubuna ait bitkilerin ise \% 2.39 ile en düşük düzeyde $\mathrm{K}$ içerdikleri belirlenmiştir. İkinci yıl elde edilen $K$ değerlerine bakımından uygulamalar arasında bir fark görülmemiştir. Farklı malç uygulamalarının bitkinin Ca konsantrasyonuna etkisi her iki yıl için de önemli bulunmakla birlikte, ilk yıl için kontrol ile B-PE uygulamaları, ikinci yıl için ise kontrol ve B-PE ile S-PE malç uygulamaları arasındaki fark anlamlı olmuştur. Malç uygulamalarının bitkinin $\mathrm{Mg}$ konsantrasyonuna etkisi ilk yıl önemsiz bulunurken ikinci yıl ise sadece S-PE uygulamasının diğerlerinden anlamlı derecede ayrıldığı belirlenmiştir. Kaçar ve Katkat (2007), kök bölgesi sıcaklığı Ca ve $\mathrm{Mg}$ alımına göre $\mathrm{K}$ alımını oransal olarak daha fazla etkilediğini bildirmişlerdir. Çalışmada ilk yıl en yüksek K konsantrasyonu siyah malç malzemesi kullanılan uygulamada elde edilmesi, araştırıcıların; sıcaklık, $\mathrm{K}$ alımına etkisini artııır savını destekler niteliktedir.

Çizelge 2. Farklı malç materyallerinin marulun kuru ağırlı̆ı (g bitki $\left.{ }^{-1}\right)$ ile $\mathrm{P}, \mathrm{K}, \mathrm{Ca}$ ve $\mathrm{Mg}$ konsantrasyonlarına etkisi (\%) Table 2. Effect of different mulch materials on dry weight of lettuce ( $g$ plant ${ }^{-1}$ ) and $P, K$, Ca and $M g$ concentrations (\%)

\begin{tabular}{lllllll}
\hline Yıl & Uygulamalar & Kuru Ağılık & $\mathrm{P}$ & $\mathrm{K}$ & $\mathrm{Ca}$ & $\mathrm{Mg}$ \\
\hline \multirow{4}{*}{2018} & S-PE & $46,99 \mathrm{~A}^{*}$ & $0.39 \mathrm{C}$ & $3.58 \mathrm{~B}$ & $1.12 \mathrm{AB}$ & $0.16 \mathrm{~A}$ \\
& S-PE & $32,23 \mathrm{~B}$ & $0,38 \mathrm{C}$ & $4.53 \mathrm{~A}$ & $1.25 \mathrm{AB}$ & $0.14 \mathrm{~A}$ \\
& B-PE & $38,94 \mathrm{AB}$ & $0.43 \mathrm{~B}$ & $2.85 \mathrm{BC}$ & $1.01 \mathrm{~B}$ & $0.13 \mathrm{~A}$ \\
& K & $32,93 \mathrm{~B}$ & $0.40 \mathrm{BC}$ & $3.12 \mathrm{BC}$ & $1.05 \mathrm{AB}$ & $0.18 \mathrm{~A}$ \\
& KONTROL & $15,05 \mathrm{C}$ & $0.50 \mathrm{~A}$ & $2.39 \mathrm{C}$ & $1.29 \mathrm{~A}$ & $0.13 \mathrm{~A}$ \\
\hline \multirow{2}{*}{2019} & S-PE & $44.40 \mathrm{~A}$ & $0.40 \mathrm{AB}$ & $1.97 \mathrm{~A}$ & $1.52 \mathrm{AB}$ & $0.28 \mathrm{~A}$ \\
& S-PE & $25.25 \mathrm{~B}$ & $0.37 \mathrm{BC}$ & $2.17 \mathrm{~A}$ & $1.38 \mathrm{~B}$ & $0.22 \mathrm{~B}$ \\
& B-PE & $36.62 \mathrm{~A}$ & $0.37 \mathrm{BC}$ & $2.44 \mathrm{~A}$ & $1.61 \mathrm{~A}$ & $0.32 \mathrm{~A}$ \\
& K & $20.05 \mathrm{BC}$ & $0.33 \mathrm{C}$ & $2.43 \mathrm{~A}$ & $1.54 \mathrm{AB}$ & $0.28 \mathrm{~A}$ \\
& KONTROL & $14.93 \mathrm{C}$ & $0.46 \mathrm{~A}$ & $2.19 \mathrm{~A}$ & $1.63 \mathrm{~A}$ & $0.32 \mathrm{~A}$
\end{tabular}

${ }^{*}$ Aynı sütunda farklı harflerle gösterilen değerler arasındaki fark istatistiksel olarak önemlidir $(p<0.005)$.

Farklı malç uygulamalarının marulun mikro element konsantrasyonlarına etkisine ait sonuçlar Çizelge 3'te verilmiştir. Çizelgeden de görüleceği üzere, her iki yıl için en yüksek bitki mikro element konsantrasyonlarının kontrol uygulamasının yapıldığı konulardan elde edildiği, diğer uygulamaların bitkinin mikro element konsantrasyonlarına olan etkilerinin ise genellikle benzer oldukları görülmüştür.

Malç uygulamaların bitkinin besin elementi konsantrasyonlarına etkisine yönelik olarak genel bir değerlendirme yapıldığında, daha düşük bitki kuru ağırlık değeri elde edilen malç konularındaki bitkilerin besin elementi konsantrasyonlarının daha yüksek olduğu görülmüştür. Buna karşılık daha fazla kuru ağırlık değeri elde edilen konulardaki bitkilerin besin elementi konsatrasyonları nisbeten daha düşük ölçülmüştür. Bu durum her iki yıl için de benzer şekilde gerçekleşmiştir. Bitkideki kuru ağırlık artışına bağlı olarak besin elementi konsantrasyonlarının azalması, artan vejetasyona bağlı olarak besin elementlerinin dokulardaki miktarlarının oransal olarak azalması şeklinde tanımlanan "seyrelme etkisi" ile açıklanabilir (Jarrell ve Beverly, 1981; Erdal ve ark., 2000; Erdal ve ark., 2014). Elde edilen besin elementi konsantrasyonları, geç dönemde bitki analizlerine bağlı yeterlilik seviyelerini bildiren çeşitli araştırma sonuçlarıyla karşılaştırıldığında genel itibarıyla bitkilerdeki besin elementi düzeylerinin yeterli olduğu 
görülmektedir (Jones ve ark., 1991; Hochmuth ve ark., 1991; Ludwick, 2002; Hartz ve ark., 2007)

Çizelge 3. Farklı malç materyallerinin marulun $\mathrm{Fe}, \mathrm{Zn}, \mathrm{Mn}$ ve $\mathrm{Cu}$ konsantrasyonlarına etkisi $\left(\mathrm{mg} \mathrm{kg}^{-1}\right)$ Table 3. Effect of different mulch materials on Fe, $\mathrm{Zn}, \mathrm{Mn}$ and Cu concentrations of lettuce $\left(\mathrm{mg} \mathrm{kg}^{-1}\right)$

\begin{tabular}{llllll}
\hline YIl & Uygulamalar & $\mathrm{Fe}$ & $\mathrm{Zn}$ & $\mathrm{Mn}$ & $\mathrm{Cu}$ \\
\hline \multirow{4}{*}{2018} & Ş-PE & $95.9 \mathrm{~B}^{*}$ & $41.9 \mathrm{~B}$ & $54.7 \mathrm{~A}$ & $14.0 \mathrm{AB}$ \\
& S-PE & $92.5 \mathrm{~B}$ & $44.9 \mathrm{~B}$ & $59.6 \mathrm{~A}$ & $11.8 \mathrm{BC}$ \\
& B-PE & $104.6 \mathrm{AB}$ & $47.9 \mathrm{~B}$ & $59.1 \mathrm{~A}$ & $11.0 \mathrm{C}$ \\
& K & $100 \mathrm{AB}$ & $42.2 \mathrm{~B}$ & $56.8 \mathrm{~A}$ & $11.4 \mathrm{BC}$ \\
& KONTROL & $113.8 \mathrm{~A}$ & $74.7 \mathrm{~A}$ & $60.4 \mathrm{~A}$ & $15.3 \mathrm{~A}$ \\
\hline \multirow{6}{*}{2019} & S-PE & $96.4 \mathrm{C}$ & $38.8 \mathrm{AB}$ & $46.0 \mathrm{BC}$ & $10.0 \mathrm{~B}$ \\
& S-PE & $94.2 \mathrm{C}$ & $34.8 \mathrm{~B}$ & $40.8 \mathrm{C}$ & $13.7 \mathrm{~A}$ \\
& B-PE & $118.6 \mathrm{~A}$ & $36.5 \mathrm{~B}$ & $55.9 \mathrm{AB}$ & $10.7 \mathrm{AB}$ \\
& K & $96.4 \mathrm{C}$ & $36.5 \mathrm{~B}$ & $52.2 \mathrm{ABC}$ & $10.1 \mathrm{~B}$ \\
& KONTROL & $130.2 \mathrm{~A}$ & $48.5 \mathrm{~A}$ & $65.2 \mathrm{~A}$ & $13.8 \mathrm{~A}$ \\
\hline
\end{tabular}

*aynı sütunda farkıı harflerle gösterilen değerler arasındaki fark istatistiksel olarak önemlidir $(p<0.005)$.

\section{Besin elementi alımları}

Malç uygulamalarının marulun topraktan kaldırdığı P, K, Ca ve Mg miktarlarına etkileri her iki yıl için de önemli bulunmuştur (Çizelge 4). Anılan tablonun incelenmesinden de görüleceği gibi marul bitkisinin topraktan kaldırdığı $\mathrm{P}, \mathrm{K}, \mathrm{Ca}$ ve $\mathrm{Mg}$ üzerine kontrol grubundan elde edilen verilerin diğer uygulamalarla karşılaştırıldığında, Ş-PE malç uygulamasıyla B-PE uygulamalarının en etkili uygulamalar olduğu belirlenmiştir. Malç uygulamalarının marul bitkisinin topraktan almış olduğu mikro element miktarı üzerine etkisi, makro element alımlarına benzer şekilde gerçekleşmiştir. Bütün malç uygulamaları altında bitkinin aldığı $\mathrm{Fe}, \mathrm{Zn}, \mathrm{Mn}$ ve Cu miktarları farklılık gösterirken bu farklılıklar istatistiksel olarak anlamlı bulunmuştur (Çizelge 5). Marul bitkisi tarafından gerçekleştirilen en düşük mikro element alımı, makro elementlerde olduğu gibi kontrol gruplarında yetişen bitkiler tarafından gerçekleştirilmiştir. Buna karşılık en yüksek mikro element alımları ise yine Ş-PE malç ile B-PE uygulamalarının yapıldığı gruba ait bitkiler tarafından gerçekleştirilmiştir.

Çizelge 4. Farklı malç materyallerinin marulun $\mathrm{P}, \mathrm{K}, \mathrm{Ca}$ ve $\mathrm{Mg}$ alımına etkisi (mg bitki ${ }^{-1}$ ) Table 4. Effect of different mulch materials on $P, K, C a$ and $\mathrm{Mg}$ uptake of lettuce ( mg plant $^{-1}$ )

\begin{tabular}{llllll}
\hline YII & Uygulamalar & P & K & Ca & Mg \\
\hline \multirow{2}{*}{2018} & S-PE & $183 \mathrm{~A}^{*}$ & $1682 \mathrm{~A}$ & $530 \mathrm{~A}$ & $75 \mathrm{~A}$ \\
& $\mathrm{~S}-\mathrm{PE}$ & $122 \mathrm{~B}$ & $1460 \mathrm{AB}$ & $403 \mathrm{~B}$ & $46 \mathrm{~B}$ \\
& B-PE & $167 \mathrm{~A}$ & $1110 \mathrm{~B}$ & $392 \mathrm{~B}$ & $52 \mathrm{AB}$ \\
& K & $132 \mathrm{~B}$ & $1027 \mathrm{~B}$ & $347 \mathrm{~B}$ & $58 \mathrm{~B}$ \\
& KONTROL & $75 \mathrm{C}$ & $360 \mathrm{C}$ & $198 \mathrm{C}$ & $20 \mathrm{C}$ \\
\hline \multirow{2}{*}{2019} & S-PE & $178 \mathrm{~A}$ & $875 \mathrm{~A}$ & $675 \mathrm{~A}$ & $124 \mathrm{~A}$ \\
& S-PE & $93 \mathrm{C}$ & $547 \mathrm{~B}$ & $348 \mathrm{~B}$ & $55 \mathrm{~B}$ \\
& B-PE & $135 \mathrm{~B}$ & $879 \mathrm{~A}$ & $590 \mathrm{~A}$ & $117 \mathrm{~A}$ \\
& K & $66 \mathrm{C}$ & $487 \mathrm{BC}$ & $309 \mathrm{~B}$ & $56 \mathrm{~B}$ \\
& KONTROL & $69 \mathrm{C}$ & $327 \mathrm{C}$ & $243 \mathrm{~B}$ & $48 \mathrm{~B}$
\end{tabular}

*Aynı sütunda farklı harflerle gösterilen değerler arasındaki fark istatistiksel olarak önemlidir ( $\mathrm{p}<0.005)$. 
Bitkinin topraktan kaldırdığı besin elementi miktarları malç uygulanan konularda kontrole göre daha fazla olduğu belirlenmiştir. Bu durum bitki kuru ağırlıklarıyla benzerlik göstermektedir. Malç uygulamaları altında artan besin elementi alımı, malç uygulamalarının bitki gelişimine olan pozitif katkılarından kaynaklandığı düşünülmektedir. Örneğin, malçlama sonucu azalan yabancı ot miktarı, esas bitkinin su ve besin elementine ortak olmasını engellediği gibi bitkilere rahat bir gelişme ortamı sağlar (Mutetwa ve Mtaita, 2014; Zangoueinejad ve ark., 2018). Böylelikle bitkilerin daha fazla besin elementi almalarını ve sonuçta daha iyi gelişmeleri sağlanır. Ayrıca malçlamayla azaltılan yabancı ot ve miktarı olası hastalık ve zararlılara konukçu ortam bulmasının da önüne geçmektedir (Zhao ve ark., 2014). Böylelikle bitkiler daha sağlıklı gelişmek suretiyle daha fazla kök ve yeşil aksam oluşturmaktadır. Bu durum bitkilerin topraktaki besin elementlerinden daha fazla yararlanmasına ve sonuçta daha fazla besin elementi sömürmesine neden olacaktır (Khazaei ve ark., 2013). Ayrıca malçlama sonucunda oluşan yüksek toprak sıcaklıkları bitki kök gelişimini arttırmak suretiyle bitkilerin daha fazla besin elementi almalarına yardımcı olmaktadır (Yordanova ve Nikoloy, 2017). Bunlara ilaveten malçlama organik maddenin mineralizasyonunu hızlandırmak suretiyle de bitkilerin mineral beslenmesine ve gelişimine önemli katkı yapmaktadır (Marschner, 1986).

Çizelge 5. Farklı malç materyallerinin marulun $\mathrm{Fe}, \mathrm{Zn}, \mathrm{Mn}$ ve $\mathrm{Cu}$ alımına etkisi (mg bitki ${ }^{-1}$ ) Table 5. Effect of different mulch materials on Fe, $\mathrm{Zn}, \mathrm{Mn}$ and $\mathrm{Cu}$ uptake of lettuce (mg plant ${ }^{-1}$ )

\begin{tabular}{llllll}
\hline YIl & Uygulamalar & $\mathrm{Fe}$ & $\mathrm{Zn}$ & $\mathrm{Mn}$ & $\mathrm{Cu}$ \\
\hline \multirow{4}{*}{2018} & Ş-PE & $4.51 \mathrm{~A}^{*}$ & $1.98 \mathrm{~A}$ & $2.60 \mathrm{~A}$ & $0.65 \mathrm{~A}$ \\
& $\mathrm{~S}-\mathrm{PE}$ & $2.97 \mathrm{C}$ & $1.45 \mathrm{AB}$ & $1.92 \mathrm{~A}$ & $0.38 \mathrm{~B}$ \\
& B-PE & $4.1 \mathrm{AB}$ & $1.86 \mathrm{~A}$ & $2.30 \mathrm{~A}$ & $0.43 \mathrm{~B}$ \\
& K & $3.29 \mathrm{BC}$ & $1.42 \mathrm{AB}$ & $1.88 \mathrm{~A}$ & $0.37 \mathrm{~B}$ \\
& KONTROL & $1.71 \mathrm{D}$ & $1.12 \mathrm{~B}$ & $0.91 \mathrm{~B}$ & $0.23 \mathrm{C}$ \\
\hline \multirow{3}{*}{2019} & Ş-PE & $4.34 \mathrm{~A}$ & $1.72 \mathrm{~A}$ & $2.04 \mathrm{~A}$ & $0.44 \mathrm{~A}$ \\
& S-PE & $2.38 \mathrm{~B}$ & $0.89 \mathrm{~B}$ & $1.03 \mathrm{~B}$ & $0.34 \mathrm{~A}$ \\
& B-PE & $4.34 \mathrm{~A}$ & $1.33 \mathrm{~A}$ & $2.05 \mathrm{~A}$ & $0.39 \mathrm{~A}$ \\
& K & $1.93 \mathrm{~B}$ & $0.75 \mathrm{~B}$ & $1.05 \mathrm{~B}$ & $0.20 \mathrm{~B}$ \\
& KONTROL & $1.92 \mathrm{~B}$ & $0.72 \mathrm{~B}$ & $0.97 \mathrm{~B}$ & $0.21 \mathrm{~A}$
\end{tabular}

*aynı sütunda farklı harflerle gösterilen değerler arasındaki fark istatistiksel olarak önemlidir $(p<0.005)$

Sonuç olarak, kaldırılan besin elementi miktarlarının, yapılan farklı malç uygulamalarına göre değiştiği görülmüştür. En fazla besin elementi alımı, genellikle Ş$\mathrm{PE}$ malç ve B-PE malç uygulamasında gerçekleşmiştir. Bu durum bitki kuru ağırlıklarıyla benzerlik göstermektedir. Buradan hareketle topraktan alınan besin elementi miktarları üzerine verim ve bitki kuru ağırlık değerlerinin daha etkili olduğunu söylemek mümkündür. Yapılan malç uygulamalarının tamamında bitkilerin topraktan daha fazla besin elementi kaldırdığı görülmüştür. Bu durum malç uygulaması yapılan bitkilerin daha fazla besin elementi ihtiyacı duyacağını göstermektedir. Bu nedenle malçlama yapılan ortamlarda, daha dikkatli bir gübreleme programı hazırlanması önerilir.

\section{ÖZET}

Amaç: Bu çalışmada, farklı renk ve özellikte plastik (PE) ve kumaş malzemenin malç malzemesi olarak kullanımının marul bitkisinin gelişimi ve mineral beslenmesine olan etkisinin belirlenmesi amaçlanmıştır. Yöntemler ve Bulgular: Araştırma, 2018-2019 yıllarında sera koşullarında 2 yıl süre ile yürütülmüştür. Çalışma; 3 farklı PE malç malzemesi, gözenekli kumaş malzeme ile kontrol uygulamalarından oluşturulmuştur. Denemede bitki materyali olarak marul bitkisi yetiştirilmiştir. Yetiştiricilik periyodu sonunda hasat edilen marul bitkisinde kuru ağırlık değerleriyle $\mathrm{P}, \mathrm{K}, \mathrm{Ca}, \mathrm{Mg}, \mathrm{Fe}, \mathrm{Zn}$, $\mathrm{Mn}$ ve $\mathrm{Cu}$ analizleri yapılarak uygulamalar arasındaki farklılıklar ortaya konulmuştur. Her iki yıl için de bitki kuru ağırlığı üzerine kontrol grubunda elde edilen verilerin diğer uygulamalar ile karşılaştırıldığında en etkili malç uygulamaların şeffaf PE malç ile balonlu PE malç 
uygulamaları olduğu belirlenmiştir. Uygulamaların bitkilerin $\mathrm{P}$ ve Ca konsantrasyonuna etkileri her iki yıl için de anlamlı bulunurken, $\mathrm{K}$ ve $\mathrm{Mg}$ konsantrasyonlarına etkileri sadece bir yıl için anlamlı bulunmuştur. Uygulamaların bitkinin mikro element konsantrasyonları üzerine etkileri her iki yıl için de genellikle önemli bulunmuştur. Kaldırılan besin elementi miktarlarının, yapılan farklı malç uygulamalarına göre değiştiği belirlenmiştir. Genel bir değerlendirme yapılacak olursa, en fazla besin elementi alımının Ş-PE malç ve B-PE malç uygulamaları altında yetişen bitkiler tarafından gerçekleştirildiği görülmüştür.

Genel Yorum: Her iki yıl için marul bitkisinde en yüksek mikro element konsantrasyonlarıkontrol uygulamasından elde edildiği, diğer uygulamaların bitkinin mikro element konsantrasyonlarına olan etkilerinin ise genellikle benzer oldukları görülmüştür.

Çalışmanın Önemi ve Etkisi: Malç uygulamaların bitkinin besin elementi konsantrasyonlarına etkisine yönelik olarak genel bir değerlendirme yapıldığında, daha düşük bitki kuru ağırlık değeri elde edilen malç konularındaki bitkilerin besin elementi konsantrasyonlarının daha yüksek olduğu görülmüştür. En fazla besin elementi alımı, genellikle şeffaf PE malç ve balonlu PE malç uygulamasında gerçekleşmiştir.

Anahtar Kelimeler: Balonlu PE malç, kumaş malç, marul, mineral beslenme.

\section{ÇIKAR ÇATIŞMA BEYANI}

Yazar(lar) çalışma konusunda çıkar çatışmasının olmadığını beyan eder.

\section{ARAŞTIRMACILARIN KATKI ORANI BEYANI}

Yazarlar çalışmaya eşit oranda katkı sağlamış olduklarını beyan eder.

\section{KAYNAKLAR}

Amare G, Desta B (2021) Coloured plastic mulches: impact on soil properties and crop productivity. Chem. Biol. Technol. Agric. 8(4): 1-9.

Asaduzzaman MD, Shamima S, Arfan MD (2010) Combined effect of mulch materials and organic manure on the growth and yield of lettuce. J. Am. Eu. Agric. Environ. Sci. 9(5): 504-508.

Barton CJ (1948) Determination of phosphorus as molybdovanadophosphoric acid. Analy. Chem. 20: 1068.

Cahill A, Chalker-Scott L (2005) Wood-chip mulch improves plant survival and establishment at no- maintenance restoration site (Washington). Ecol. Restor. 23: 212-213.

Caruso G, Stoleru V, De Pascale S, Cozzolino E, Pannico A, Giordano M, Teliban G, Cuciniello A, Rouphael Y (2019) Production, leaf quality and antioxidants of perennial wall rocket as affected by crop cycle and mulching type. J. Agron. 9: 194-202.

Decoteau DR, Kasperbauer MJ, Daniels DD, Hunt PG (1988) Plastic mulch color effects on reflected light and tomato plant growth. Sci. Hortic. 34: 169-175.

Erdal I, Bozkurt MA, Mesut KM, Karaca S, Saglam M (2000) Effects of humic acid and phosphorus applications on growth and phosphorus uptake of corn plant (Zea mays L.) grown in a calcareous soil. Turk J Agric For. 24: 663-668.

Erdal I, Kaya M, Küçükyumuk Z (2014) Effects of zinc and nitrogen fertilizations on grain yield and some parametters effecting zinc bioavailability in lentil seeds. Legum. Res. 37(1): 55-61.

Engels C, Marschner H (1992) Root to shoot translocation of macronutrients in relation to shoot demand in maize grown at different root zone temperature. J Plant Nutr. Soil Sci. 155: 121-128.

Franquera EN (2015) Effects of plastic mulch color on the total soluble solids, total sugars and chlorophyll content of lettuce (Lactuca sativa L). Int. J. Agric. Res. 2: 18-24.

Ham JM, Kluitenberg GJ, Lamont WJ (1993) Optical properties of plastic mulches affect the field temperature regime. J. Am. Soc. Hortic. Sci. 118: 188193.

Hartz TK, Johnstone PR, Williams E, Smith RF (2007) Establishing lettuce leaf nutrient optimum ranges through DRIS analysis. HortScience 42(1): 143-146.

Haque MA, Jahiruddin M, Clarke D (2018) Effect of plastic mulch on crop yield and land degradation in south coastal saline soils of Bangladesh. Int. Soil Water Conserv. Res. 6: 317-324.

Hochmuth G, Maynard D. Vavrina C, Hanlon E (1991) Plant Tissue Analysis and Interpretation for Vegetable Crops in Florida Univ. Florida Special Publication SSVEC42.

Ghosh PK, Dayal D, Bandyopadhyay KK, Mohanty M (2006) Evaluation of straw and polythene mulch for enhancing productivity of irrigated summer groundnut. Field Crops Res. 99: 76-86.

Jarrell WM, Beverly RB (1981) The dilution effect in plant nutrition studies. Adv. Agron. 34: 197-224.

Jones Jr, J. B., Wolf, B., \& Mills, H. A. (1991). Plant analysis handbook. A practical sampling, preparation, analysis, and interpretation guide. Micro-Macro Publishing, Inc. 
Kaçar B, Katkat V (2007) Bitki Besleme. Nobel Yayın, No:849, 678s.

Kacar B.İnal A (2010) Bitki Analizleri (2. Baskı). Nobel Yayınları, 1241: 123-169.

Kader MA, Senge M, Mojid MA, Ito K (2017) Recent advances in mulching materials and methods for modifying soil environment. Soil Till. Res. 168: 155166.

Khazaei I, Salehi R, Kashi A, Mirjalili SM (2013) Improvement of lettuce growth and yield with spacing, mulching and organic fertilizer. Int. J. Agric. Crop Sci. 6(16): 1137-1143.

Li Q, Li H, Zhang L, Zhang S, Chen Y (2018) Mulching improves yield and water-use efficiency of potato cropping in China: a meta-analysis. Field Crop Res. 221: 50-60.

Lindsay WL, Norvell WA (1969) Development of a DTPA micronutrient soil test. Soil Sci. Soc. Am. Proceed. 35: 600-602.

Ludwick AE (2002) Western Fertilizer Handbook. 9th ed. Interstate Publishers, Inc., Danville.

Marschner H (1986) Mineral Nutrition of Higher Plants. Academic Press. London.

Mendonça SR, Ribeiro MCA, Vital RG, Evangelista ZR, Pontes NC, Nascimento AR (2021) The effect of different mulching on tomato development and yield. Sci. Hortic. 275: 109657.

Moniruzzaman M (2006) Effects of plant spacing and mulching on yield and profitability of lettuce (Lactuca sativa L.). J. Agric. Rural Dev. 4(1): 107-111.

Moreno MM, Cirujeda A, Aibar J, Moreno C (2016) Soil thermal and productive responses of biodegradable mulch materials in a processing tomato (Lycopersicon esculentum Mill.) crop. Soil Res. 54: 207-215.

Mutetwa M, Mtaita T (2014) Effects of mulching and fertilizer sources on growth and yield of onion. JGIASS. 2: 102-106.
Olsen SR, Cole CV, Watanable FS, Dean LA (1954) Estimation of Available Phosphorus in Soils by Extraction with Sodium Bicarbonate. U.S. Dept. of Agric. Cir. 939, Washington D.C.

Richards LA (1954) Diagnosis and Improvement of Saline and Alkali Soils. Soil Sci. 78: 2.

Steinmetz Z, Wollmann C, Schaefer M, Buchmann C, David J, Trooger J, Munoz K, Fror O, Schaumann GE (2016) Plastic mulching in agriculture. Trading shortterm agronomic benefits for long-term soil degradation. Sci. Total Environ. 550: 690-705.

Walkley A, Black IA (1934) An examination of the degtjareff method for determining soil organic matter, and a proposed modification of the chromic acid titration method. Soil Sci. 37(1): 29-38.

Wang X, Jia Z, Liang L, Yang B, Ding R, Nie J, Wang J (2016) Impacts of manure application on soil environment, rainfall use efficiency and crop biomass under dryland farming. Sci. Rep. 6: 1-8.

Yordanova M, Nikolov A (2017) Influence of plant density and mulching on growth and yield of lettuce (Lactuca sativa var. romana L.). Int. J. Agric. Environ. Res. 3(10): 10-14.

Zangoueinejad R, Kazemeini SA, Ghadiri H, Javanmardi J (2018) Effects of non-living mulches and metribuzin on yield and yield components of tomato (Lycopersicon escolentum cv. CH). Iran Agric. Res. 37: 43-48.

Zhao H, Wang RY, Ma BL, Xiong YC, Qiang SC, Wang CL (2014) Ridge-furrow with full plastic film mulching improves water use efficiency and tuber yields of potato in a semiarid rainfed ecosystem. Field Crops Res. 161: 137-148. 